\title{
A LITERATURA COMO DESTINO, MESMO EM TEMPOS DE PANDEMIA
}

The literature as a destiny, even in pandemic times

Bianca Rosina Mattia

Dttps://orcid.org/0000-0002-0136-1241

Daniela Stoll

https://orcid.org/0000-0001-8843-779X

Elton da Silva Rodrigues

https://orcid.org/0000-0002-1890-7482

Isabele Soares Parente

(iD) https://orcid.org/0000-0003-0561-5488

Jair Zandoná

https://orcid.org/0000-0002-4301-9436

\section{Tânia Regina Oliveira Ramos}

(iD) http://orcid.org/0000-0002-2477-0419

Universidade Federal de Santa Catarina, Programa de Pós-Graduação em Literatura,

Florianópolis, SC, Brasil, 88040-900

Quando, em meados de 2019, a partir das reuniões da comissão editorial da Anuário de Literatura, as chamadas que situariam os dois números de 2020 da revista foram pensadas, o contexto no qual vivíamos e a situação em que nos encontrávamos eram bastante diversas. Estávamos interessados em pensar os corpos e suas representações no literário - e o dossiê Ficções queer brasileiras contribui para o debate, assim como as poéticas da voz, que terá espaço no segundo número deste ano. Mas fomos interpelados pela expansão do Covid-19 no Brasil, com a necessidade de mantermos distanciamento social, e acompanhamos o aumento de números de casos e, lastimavelmente, de óbitos - são vidas que importam e que precisam ser contadas, como é o caso do projeto Inumeráveis: Memorial dedicado à história de cada uma das vítimas do coronavírus no Brasil, disponível on-line em https://inumeraveis.com.br/.

São muitas experiências, processos, formas de viver e de se relacionar que estão sendo

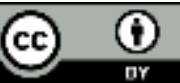

Esta obra está licenciada sob uma Creative Commons - Atribuição 4.0 
constante e incessantemente tensionados. O imaginário dos "monstros invisíveis" (SANT'ANNA, 2020) do século XIX tomou outras proporções na medida que, em pleno século XXI, tivemos que aprender a lavar as mãos, ao uso de máscaras, de álcool, de manter dois metros de distância entre as pessoas quando fora de casa. Os efeitos de trabalharmos em casa, para nós, envolvidos com a pós-graduação, sem poder acessar os espaços físicos da universidade, são desafiadores. Há não apenas o cuidado de si, mas também - e sobretudo - do e com o outro.

A pandemia não permite que consideremos o cenário atual a partir de um regime de normalidade. Não há como. Temos, considerando nosso compromisso com a UFSC, uma universidade pública, gratuita e de qualidade, atuando (não apenas) no âmbito do Programa de Pós-Graduação em Literatura, mas também em outras esferas que englobam pesquisa, ensino e extensão. Daí porque nossos esforços para viabilizar a publicação deste número - e para isso contamos, além da comissão editorial, com o apoio de pesquisadores e pesquisadoras que aceitaram realizar parecer, com a equipe do Portal de Periódicos e outras instâncias da universidade que contribuem para que a Anuário exista e seja publicada -, mas também temos participado de reuniões, de lives (como o projeto PPGLIT Live, disponível em https://www.instagram.com/ppglitufsc/), mesas virtuais, grupos de estudo, bancas, trabalhado nas dissertações, teses, artigos... Na tela do computador, a cada encontro virtual, vemos muitos rostos em seus respectivos quadrados, pixelizados, sem poder acessar suas expressões, gestos, com sucesso. Há muita energia pessoal dedicada. Dependemos das conexões de internet para mantermos nossa rede de afetos, de trabalho, de estudos. Embora distantes fisicamente, mantemos o senso de coletividade que aprendemos, de muitas e diferentes formas, também com a literatura.

Em tempos mediados pelo virtual, quisemos, com esta edição, garantir que as vozes das pesquisadoras e dos pesquisadores que contribuíram com o número pudessem ser acessadas. Suas pesquisas, assim como as nossas e de tanta/os outras/os colegas, estudantes da pósgraduação, pesquisadoras/es, docentes possam circular, fazer ler. Nossa revista, vale lembrar, "proporciona acesso público a todo seu conteúdo, seguindo o princípio de que tornar gratuito o acesso a pesquisas gera um maior intercâmbio global de conhecimento" ${ }^{1}$. Motivar, de algum modo, mesmo em tempos de pandemia, o acesso ao conhecimento produzido.

Nesse sentido, o primeiro número do volume 25 da revista Anuário de Literatura busca conduzir as leitoras e os leitores pelo universo queer nas ficções literárias brasileiras com o dossiê, organizado por Marcio Markendorf (professor na UFSC) e Geovana Quinalha de Oliveira (professora na UFMS). Embora essas discussões teóricas sejam debatidas há muito na academia nas diferentes áreas acadêmicas, ainda são escassas sobre as ficções que tratam acerca da representação e da representatividade de personagens queer na literatura brasileira contemporânea. Quanto à capa desta edição, elaborada a partir de uma fotografia de Sarah Lötscher com edição de Marcio Markendorf, tem como destaque o arco-íris. As bandeiras de

1 ANUÁRIO DE LITERATURA. Declaração de Direito Autoral. Disponível em: https://periodicos.ufsc.br/index.php/literatura/about/submissions\#copyrightNotice. Acesso em: 02/06/2020.

Anu. Lit., Florianópolis, v. 25, n. 1, p. 08-12, 2020. ISSNe 2175-7917 
arco-íris foram e continuam sendo erguidas durante paradas que celebram o orgulho LGBT+ como símbolo não apenas de orgulho de pertencimento à comunidade, mas também de união, pelo conjunto das diferentes cores que refletem a diversidade da comunidade. Dentre desse contexto de luta e resistência, consideramos significativo a publicação deste número no mês de junho, conhecido como pride month (mês do orgulho) por conta da Rebelião de Stonewall, marco zero da conquista dos direitos LGBT+ e evento que proporcionou maior visibilidade a luta pelos diretos desta comunidade.

Nesse sentido, dentre os variados textos que compõem esta edição, as expressões de gênero e as configurações de corpos dissidentes dos modelos hetero(cis)normativos são temas recorrentes de análise. Como corpus literário, as produções de Carol Bensimon, Sylvia Orthof, Natália Polesso, Diedra Roiz, Nelson Rodrigues, Caio Fernando Abreu são analisadas por diferentes perspectivas. Daniele Gallindo Gonçalves Silva e Jessé Carvalho Lebkuchen analisam a viagem das protagonistas do romance Todos Nós Adorávamos Caubói como espaço de construção da sexualidade e do autoconhecimento identitário, "queerizando", como afirmam, os locais percorridos. Antônio Augusto do Canto Lopes Filho discute sobre o sistema sexo-gênero e a heteronormatividade nas relações afetivas a partir desse romance de Bensimon. Ruan Nunes Silva, por sua vez, investiga a fragmentação e deslocamento das identidades das protagonistas para discutir a própria indefinibilidade teórica da teoria queer na literatura contemporânea.

Vanessa Ferreira Vieira e Eurídice Figueiredo analisam três contos da escritora Natalia Borges Polesso, que fazem parte de Amora - "Vó, a senhora é lésbica", "Marília acorda" e "As tias" -, a fim de pensar sobre a representação de casais lésbicos na literatura brasileira contemporânea, a partir dos estudos de Monique Wittig, Adrienne Rich e Judith Butler. O amor entre mulheres é também tema do estudo de Manuela Rodrigues Santos que, a partir dos contos "Minha prima está na cidade", "Como te extraño, Clara", "Diáspora lésbica" e "Dramaturga hermética", também de Polesso, investiga as figurações do amor lésbico na contemporaneidade. As inquietações sobre esse tema são igualmente objeto de estudo de Eliane Santos da Silva e Rosana Cássia dos Santos ao proporem uma leitura do conto "Duas mulheres sozinhas", de Diedra Roiz, para compreender o peso do heterocentrismo na experiência individual das personagens.

O artigo de Emerson Silvestre Lima da Silva investiga a desconstrução dos arquétipos binários de gênero e performatividade no romance $O$ fantasma travesti, de Sylvia Orthof, tecendo uma análise sobre as ambiguidades e inconstâncias conceituais do queer. No tocante à configuração de corpos abjetos, Paulo Valente analisa o conto-crônica "Delicado", de Nelson Rodrigues, para discutir os reflexos da sociedade heteronormativa compulsória na narração, enfatizando a pressão social em torno do exercício da masculinidade.

O disciplinamento dos corpos e a estigmatização da homossexualidade são temas tratados também por Renata Farias de Felippe e João Alcides Haetinger Esmerio. Para tanto, revisitam a produção literária brasileira nos anos de 1980, a partir de dois contos do escritor Caio Fernando Abreu, para analisar os desdobramentos da AIDS na literatura, com base nos 
apontamentos de Susan Sontag, no contexto brasileiro. O tema é retomado por Alessandra Daniele da Silva Boos com o romance de Michel Laub para investigar a estigmatização do HIV no discurso narrativo do protagonista, José Victor.

Além dos artigos que compõem o Dossiê, o número também conta com contribuições de Naiara Sales Araújo, sobre a obra de Ruth Bueno, a fim de refletir acerca da ficção científica de autoria feminina, gênero historicamente marginalizado na literatura brasileira. Por fim, Cristóvão Santos Júnior investiga alguns vestígios do experimentalismo literário greco-latino, abordando tipologias de escrita constrangida, para compreender a potência estilística dessas manifestações artísticas.

Essas possibilidades de ler o literário sinalizam alguns dos resultados de pesquisas que têm sido feitas nos Programas de Pós-Graduação, seja na UFSC, na UFMS, na UFPel, no IFPE, na UFF, na UnB, UESPI, na UFSM, na UFMA, na UFBA, instituições representadas neste número. Queremos, ainda, registrar nosso agradecimento pela atuação até o início deste ano da colega Marina Siqueira Drey, que se encontra dedicada à tese, e reforçar nossos agradecimentos à Equipe do Portal de Periódicos da Biblioteca Universitária da UFSC pelo suporte e apoio para esta publicação.

\section{Referência}

SANT'ANNA, Denise Bernuzzi de. Lavar as mãos, descolonizar o futuro. \#PandemiaCrítica, n. 006, N1-Edições, São Paulo, 26 de março de 2020. Disponível em: https://n1edicoes.org/006. Acesso em: 30/05/2020.

\section{NOTAS DE AUTORIA}

Bianca Rosina Mattia (biancamattia@gmail.com) é doutoranda em Literatura no Programa de Pós-Graduação em Literatura da UFSC. Mestra em Literatura (PPGLit/UFSC). Licenciada em Letras-Língua Portuguesa e Literaturas (UFSC). Bacharela em Ciências Jurídicas e Sociais (UPF). Integra o quadro discente do Núcleo de Literatura Atual - Estudos Feministas e PósColoniais de Narrativas da Contemporaneidade (LITERATUAL/UFSC). Compõe a Comissão Editorial da revista Anuário de Literatura e tem interesse em Literatura Portuguesa (séc. XX e XXI) e Estudos Literários sob a perspectiva dos Estudos de Gênero e da Crítica Feminista.

Daniela Stoll (sstolldaniela@gmail.com) é doutoranda em Literatura no Programa de PósGraduação em Literatura da Universidade Federal de Santa Catarina (UFSC) e Mestra em Literatura pela mesma universidade (2017). É membro da comissão editorial da Revista Anuário de Literatura (PPGL/UFSC) e integrante do Núcleo Literatual. Graduou-se em Arquitetura e Urbanismo (UFSC, 2010) e desde 2018 cursa a graduação em Letras, Língua Portuguesa e Literaturas, também na UFSC. É autora do romance Do lado de dentro do mar (Editora Patuá, 2018).

Elton da Silva Rodrigues (eltonrodriguesdsr@gmail.com) é licenciado em Letras - Língua Portuguesa e Literatura pela UFSC e integrante do LabFlor: Laboratório Floripa em composição 
transdiciplinar: arte, cultura e política. Mestrando em Literatura pelo Programa de Pósgraduação em Literatura da Universidade Federal de Santa Catarina (UFSC) e bolsista CNPq.

Isabele Soares Parente (isabele.soares.p@gmail.com) é mestranda em Literatura pela UFSC. Possui graduação em Letras - Língua Portuguesa pela Universidade Regional do Cariri (URCA). É pesquisadora do Núcleo de Estudos em Teoria Linguística e Literária (NETLLI) e participa do Laboratório de Estudos de Gênero e História (LEGH) e do Núcleo de Pesquisa em Cultura Popular Behetçoho. Possui interesse nos temas: estudos feministas e pós-coloniais, narrativas contemporâneas e cultura popular.

Jair Zandoná (jzandona@gmail.com) é doutor e mestre em Literatura pela Universidade Federal de Santa Catarina. É um dos editores da Revista Anuário de Literatura (PPGL/UFSC), editor de resenhas da Revista Estudos Feministas (REF), integra o quadro de pesquisadores/as associados/as do IEG/UFSC e do LITERATUAL/UFSC.

Tânia Regina Oliveira Ramos (taniareginaoliveiraramos@gmail.com) possui graduação em Letras pela UFSC, mestrado e doutorado em Literaturas de Língua Portuguesa pela PUC-RJ. Atualmente é Professora Titular e coordena o núcleo Literatura e Memória da UFSC. Faz parte da Coordenação Geral da Revista Estudos Feministas. É professora de Literatura Brasileira e Estudos Literários nos Cursos de Graduação e Pós-Graduação em Letras e Literatura na UFSC. Atua, pesquisa e publica nas linhas de pesquisa História e Memória, escritas de si e gênero.

Como citar esse artigo de acordo com as normas da revista

MATTIA, Bianca Rosina; STOLL, Daniela; RODRIGUES, Elton da Silva; PARENTE, Isabele Soares; ZANDONÁ, Jair; RAMOS, Tânia Regina Oliveira. A literatura como destino, mesmo em tempos de pandemia. Anuário de Literatura, Florianópolis, v. 25, n. 1, p. 08-12, 2020.

\section{Contribuição de autoria}

Elaboração e contribuição coletiva.

\section{Financiamento}

Não se aplica.

\section{Consentimento de uso de imagem}

Não se aplica.

\section{Aprovação de comitê de ética em pesquisa}

Não se aplica.

\section{Licença de uso}

Este artigo está licenciado sob a Licença Creative Commons CC-BY. Com essa licença você pode compartilhar, adaptar, criar para qualquer fim, desde que atribua a autoria da obra.

\section{Histórico}

Recebido em: 15/05/2020

Aprovado em: 02/06/2020

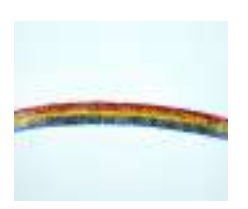

